\title{
Соотношение правовых систем. \\ Часть 1. \\ «Традиционные» доктрины соотношения международного права и внутригосударственного \\ права
}

Нефедов Б.И.*

Различные подходы к соотношению правовых систем высказывались многочисленными авторами в течение всего периода существования науки международного права, начиная с периода ее формирования, однако они первоначально были формализованы в виде «традиционных» фундаментальных теоретических концепций и доктрин только в 50-х годах XX века, причем в СССР. Само появление соответствующих теоретических конструкций, и эволюция представлений о них в дальнейшем, были вызваны существующим уровнем развития общественных отношений, а также изменениями в общественном и государственном строе и реальных интересов нашего государства в конкретных исторических условиях.

Так, русские дореволюционные авторы конца XIX - начала XX века в основном стояли в этом вопросе на позициях дуализма, а с момента создания Советского государства и вплоть до середины 50-х годов $\mathrm{XX}$ века у нас к соотношению международного и внутригосударственного права фактически господствовал государственно-монистический подход, хотя формально это на тот период выражено не было. С середины 50-х годов прошлого века советская доктрина вновь перешла на позиции дуализма. Именно в этот период в отечественной науке произошла формализация в виде «традиционных» фундаментальных теоретических концепций различных взглядов на соотношение международного и внутригосударственного права. При этом были выделены не три, как это принято считать, а четыре концепции - три буржуазных (две монистических и дуалистическая) и советская.

Ключевые слова: соотношение международного и внутригосударственного права; монистическая концепция; дуалистическая концепция; советская концепция.

\footnotetext{
* Нефедов Борис Иванович - д.ю.н., доцент, проректор Омской юридической академии по научной работе.
} 
Традиционно считается, что исторически в теории права по поводу соотношения международного и внутригосударственного права возникли и существуют три основных направления: монистическое с приматом международного права, монистическое с приматом национального права и дуалистическое, хотя каждое из них и признается внутренне не однородным. Общим для монистических концепций является то, что их представители рассматривают международное и национальное право как части единой (универсальной, мировой, глобальной) правовой системы. Они отрицают самостоятельный характер международного и национального права, исходят из тезиса о том, что в мире существует единый правопорядок, в рамках которого международное и внутригосударственное право и составляют некое единое целое.

Дуалистическое понимание основывается на признании существования двух типов взаимодействующих между собой, но самостоятельных правовых систем: международного права и внутригосударственного права. Все дуалистические концепции исходят из того, что эти разные по типу правовые системы являются составляющими права как такового, имеют единую правовую сущность, но не образуют единой (универсальной) правовой системы.

Различные подходы к соотношению правовых систем высказывались многочисленными авторами в течение всего периода существования науки международного права, начиная с периода ее формирования, однако они были формализованы в виде фундаментальных теоретических концепций и доктрин только в 50-х годах XX века. Причем формализованы не где-то в науке международного права «вообще», а именно в нашем родном государстве, и только после этого произошла их рецепция (восприятие) ученым миром за рубежом. Поэтому чтобы разобраться с представлениями о «традиционных» доктринах соотношения международного и внутригосударственного права необходимо сделать небольшой экскурс именно в отечественную историю.

В нашем государстве, в течение исторически небольшого промежутка времени, подходы к соотношению международного и внутригосударственного права неоднократно менялось кардинально.

Так, русские дореволюционные авторы конца XIX - начала XX века (В.П. Даневский, С.А. Жигарев, Н.П. Иванов, П.Е. Казанский, М.Н. Капустин, Ф.Ф. Мартенс, А.Н. Стоянов, и др.), за небольшим исключением $^{1}$, фактически стояли на позициях дуализма, хотя формально это на тот период и не было выражено 2 . 
Но теоретические концепции вообще, и теоретические концепции соотношения международного и внутригосударственного права в частности, возникают не случайно и, как правило, отражают соответствующий уровень развития общественных отношений, а также вполне реальные интересы конкретных государств в данных исторических условиях. Ф.Ф. Мартенс подчеркивал, что «изучение истории международных отношений вообще и участие в них России в особенности привело нас к непоколебимому убеждению в том, что внутренняя жизнь и порядок государства обнаруживают роковым образом свое действие на международные его отношения и политику. Международные отношения всегда представляют зеркала, точно отражающее внутреннее состояние государственных обществ в известную эпоху их существования, равно и принципов, которые лежат в основании социального и политического их строя» ${ }^{3}$.

Так и в нашей стране, с возникновением советского государства подходы к соотношению международного и внутригосударственного права коренным образом изменились. И эти изменения были фактически предопределены особенностями сформировавшегося в СССР общественного и государственного строя, а также существующим раскладом сил на мировой арене.

В этих условиях политические и экономические интересы государства (как они понимались новой властью) потребовали, скажем так, дифференцированного подхода к международному праву, дающему возможность в необходимых случаях уклониться от исполнения международных обязательств. Дуалистическая концепция такой возможности не предоставляла, зато ее предоставляла монистическая концепция в том ее варианте, что уже исповедовался на тот период (с приматом национального права над международным правом). В результате в этот период в нашей стране происходит переход от дуалистического к монистическому пониманию соотношения международного и внутригосударственного права.

За теоретическим обоснованием такого перехода дело не встало.

Господствующая в тот период в нашем государстве доктрина исходила из отправного тезиса марксизма о том, что право - есть возведенная в закон воля господствующего класса. Отсюда делался «логичный» вывод о том, что любое право - есть диктат воли одного класса другому $^{4}$. Международное право того периода, как созданное в первую очередь капиталистическими странами, рассматривалось, прежде всего, 
как буржуазное право, а потому считалось возможным средством такого диктата со стороны «мировой буржуазии». Уже поэтому, по мнению сторонников такого подхода, оно не могло быть выше права «первого в мире государства рабочих и крестьян».

Таким образом, на этом этапе развития представлений о соотношении международного и внутригосударственного права в нашем государстве стал признаваться бесспорный примат национального права (прежде всего - советского, как обладавшего более высокой социальной сущностью ${ }^{5}$ ) над международным правом. Теперь уже, по словам И.С. Перетерского, «в затруднительных случаях судья (и иной применяющий право орган) должен искать решения не в каких-либо надгосударственных критериях международного общения, а в общих началах советского законодательства и общей политике рабоче-крестьянского правительства» ${ }^{6}$. Одновременно в советской доктрине был выдвинут тезис о существовании двух международно-правовых систем - социалистической и капиталистическойㄱ. При этом широко распространенными стали суждения о том, что советское международное право «должно быть включено в систему советского права как его отрасль» ${ }^{8}$. Из этого же тезиса закономерно был сделаны выводы о том, что «международное право в эпоху общего кризиса капитализма становится одной из форм, в которой протекает борьба двух систем» ${ }^{9}$, и что «...относительная ценность международного права переходной эпохи двояка: мост между буржуазной и социалистической половинами человечества не может не рухнуть в тот самый час, когда распадутся последние устои первой. Разросшееся до размеров всемирного «междусоветское право» - таково имя его прижизненного преемника» ${ }^{10}$.

В вопросе соотношения международного и внутригосударственного права в СССР того периода, «господствовал государственно - монистический подход» ${ }^{11}$. Хотя опять же, формально это на тот период так же выражено не было.

Однако этот период закончился где-то к середине 50-х годов $\mathrm{XX}$ века, когда международная обстановка, а также место и роль Советского государства в семье народов коренным образом изменились. После победы в Великой Отечественной войне Советский Союз превратился в одну из двух сверхдержав. С созданием Организации Объединенных Наций он стал одним из пяти постоянных членов Совета Безопасности, решения которого, напомним, носят обязательный характер для всех государств - участников этой организации. К этому 
же времени относится и формирование социалистического содружества, в котором признанным лидером становится СССР. Основной целью его создания было неуклонное выполнение всеми социалистическими государствами достигнутых между собой договоренностей и выступление единым фронтом в защиту тех или иных политических ситуаций или интересов, под которыми, прежде всего, понималось неукоснительное следование в фарватере соответствующей политики нашего государства. Кроме того, к этому времени (после смены руководства страны) наступили значительные перемены в политическом режиме СССР. Крайние формы тоталитаризма были оставлены в прошлом.

Изменилась и идеология внешней политики Советского государства. Вместо идеи о перманентной революции и мирном существовании как особой форме классовой борьбы в середине 50-х гг. провозглашается новый курс - на мирное сосуществование государств с различным социальным строем. Впрочем, меняется характер и самого международного права, «не являющегося более буржуазным» ${ }^{12}$, что, в свою очередь, не могло не повлиять на отношение к нему СССР.

Со сменой парадигмы международного развития теория часто вынуждена пересматривать свои концептуальные (и методические) основы, так как они перестают соответствовать потребностям вновь наступившей эпохи. Основанная на классовом подходе идея о примате национального права над международным правом в новых условиях перестала быть (почти по Губеру) «выгодной» нашему государству.

Но в основе монистического представления о соотношении национального и международного права в предыдущий период лежала классовая теория права, которая на тот период все равно оставалась в нашем государстве единственно возможным подходом к оценке правовых явлений. Возник парадокс, который заключался в том, что отказ от монистической концепции, основанной на классовом подходе к международному праву и соотношению правовых систем, мог в тот период иметь место никак не иначе, как только опять же с ... классовых позиций.

Тогда советская международно-правовая доктрина, прежде всего, признала существование общего для всех государств международного права. Значительную роль в этом процессе сыграли работы Г.И. Тункина. Им была выдвинута теория согласования воль государств как основы нормотворчества в международном праве, сделан вывод о том, что в основе международного договора, а также международного обычая, лежит не возведенная в закон воля какого-то одного 
класса, а соглашение государств, согласование их воли, в том числе государств с противоположным социально-экономическим строем ${ }^{13}$. Но этого было явно недостаточно. Вот тогда-то и произошло «оформление» различных подходов к соотношению международного и внутригосударственного права в виде самостоятельных формально определенных концепций.

Для достижения поставленной цели таких концепций должно было быть несколько. Это, прежде всего, как минимум две буржуазные концепции, которые следовало бичевать «слева» и «справа». Ну и, конечно же, «единственно верная» концепция советских юристов-международников, которая, прежде всего, должна была полностью отвергать идею любого примата (или преимущества) национального права над международным правом. Поэтому в нашей отечественной доктрине с самого начала выделялись не три концепции соотношения международного и внутригосударственного права, как это принято считать, а четыре: три буржуазных (две монистических и дуалистическая), а также ... советская (или социалистическая). В монистической теории соотношения международного и внутригосударственного права было выделено два направления. Первое из них исходило из примата международного права ${ }^{14}$, и было представлено в виде двух основных подходов - концепции Г. Кельзена ${ }^{15}$ и концепции Ж. Сселя ${ }^{16}$, поддержанных их многочисленными сторонниками.

По мнению Г. Кельзена международное право и внутригосударственное право представляют собой часть одной и той же системы норм, сила и содержание которых логически вытекают из единой основной нормы $^{17}$. При этом международное право «может рассматриваться, если откинуть предположение о суверенности отдельных государств, как система норм, стоящая над национальными юридическими порядками и предоставляющая им равенство и соединяющая их в общеюридическом порядке» ${ }^{18}$.

Ж. Ссель же считал, что единственным субъектом международного права есть индивид, являющийся особым «правопорядком», и поэтому международное право необходимо заменить термином «право людей», которое должно стоять выше права государства и отменять его нормы в случаях противоречия. По его мнению, норма международного права может «автоматически упразднить норму национального права постольку, поскольку она с ней не совместима», а «государство 
есть правопорядок, непосредственно подчиненный международному правопорядку» ${ }^{19}$.

Несмотря на очевидные различия, объединяло эти теории то, что обе они были построены на принципе отрицания государственного суверенитета. Исходя из правильной в принципе посылки, что государство должно выполнять свои международные обязательства, они пришли к неверным выводам о том, что национальное право помимо воли и независимо от самого государства должно подчиняться международному праву.

Второе направление монистической концепции исходило из примата национального права над правом международным. Поскольку по понятным причинам речь при этом могла идти исключительно o «буржуазных апологетах», то общий подход к ней был таков: данная теория получила распространение в работах немецких ученых в конце XIX - первой половине XX века. В качестве представителей этой концепции обычно указывались Л. Цорн, М. Венцель ${ }^{20}$, Е. Кауфман ${ }^{21}$ и др. Отмечалось, что они, основываясь на взглядах Гегеля, считавшего международное право правом «внешне-государственным», рассматривали международное право как совокупность «внешне-государственных» прав различных государств. При этом обычно приводились слова А. Цорна о том, что «международное право юридически является правом лишь тогда, если и поскольку оно является государственным правом» и «нормы международные являются правовыми нормами тогда, если они проявляют себя как составная часть национального права» ${ }^{22}$. Тот факт, что в данном случае речи нет о том, что международное и внутригосударственное право составляют какую-то единую правовую систему, поскольку международному праву было вообще отказано в существовании, был проигнорирован.

О советском подходе к соотношению международного и внутригосударственного права в предыдущий период предпочитали не вспоминать. Чтобы сохранить лицо в качестве крайнего, видимо как фигуры к тому времени достаточно одиозной, был определен А.Я. Вышинский. Из работы в работу в качестве негативного примера стали переходить его цитаты о примате советского права над международным правом. При этом было объявлено, что «точка зрения Вышинского, носящая на себе заметную печать волюнтаристских концепций, не находит сторонников среди советских юристов-международников, она не соответствует всему духу советской науки международного права» ${ }^{23}$. 
В то же время был сделан общий вывод о том, что «и теория примата международного права и теория примата внутригосударственного права носят реакционный характер» ${ }^{24}$. Таким образом, позиции монизма были объявлены неверными, буржуазными и чуждыми, т.е. абсолютно неприемлемыми, в том числе (что и требовалось) с классовых позиций.

Более того, отмечалось, что в 30-х годах 20-го века идея примата внутригосударственного права над международным правом «была подхвачена юристами гитлеровской Германии». Она «изображалась ими как национал-социалистическая «доктрина» и использовалась для «обоснования» произвола германского империализма на мировой арене ${ }^{25}$. Это в целом соответствовало действительности, но подспудно, в контексте дискуссии, фактически ставило знак равенства между монистом, заявляющим о примате национального права над правом международным и пособником фашизма.

Обращает на себя внимание еще одно обстоятельство. В интересах решения одной задачи были вольно или невольно заложены основы будущей путаницы. В процессе формализации монистических концепций причудливым образом произошло совмещение разных понятий соотношений. Это, с одной стороны, соотношение абстрактной совокупности всех правовых систем в рамках общего понятия права и, с другой стороны, соотношения национального права конкретного государства и тех норм международного права, что являются для данного государства обязательными (в аспекте реализации предписаний международных норм опять же в данном государстве). Второе для каждой страны является индивидуальным. Признаки общего допустимо переносить на специальное и индивидуальное, перенесение же признаков индивидуального, то есть того, что выделяет данный предмет именно как индивидуальное, на общее недопустимо. Это обстоятельство еще скажется на характеристике «традиционных» доктрин соотношения правовых систем в дальнейшем.

Что касается дуалистического направления, то в качестве его основателей обычно указывались Г. Трипель, Д. Анцилотти и Л. Оппенгейм. Считалось, что они рассматривали международное и национальное право как абсолютно самостоятельные правовые системы, в силу чего те не могли пересекаться или вступать в конфликт. В подтверждение этого обычно приводилась следующая цитата Г. Трипеля: «Международное и внутригосударственное право суть не только различные отрасли права, но и различные правопорядки. Это два круга, которые тесно 
не соприкасаются, но никогда не пересекаются ...Отношения, которые регулирует внутреннее право, являются непригодным объектом для международно-правового регулирования и наоборот» ${ }^{26}$. Иногда цитировался и другой известный дуалист - Д. Анцилотти, который также писал, что «международное и внутригосударственное право ... представляют собой отдельные правопорядки» ${ }^{27}$, и потому отрицал возможность коллизий между международными и внутренними нормами ${ }^{28}$.

В то же время всегда подчеркивалось, что в отличие от монистов дуалисты считали, что международное право «есть право не над суверенными государствами, а между ними» ${ }^{29}$.

В целом отношение к дуалистической концепции было достаточно снисходительным. Она была признана не реакционной, а «буржуазно-демократической», при этом отмечалось, что в дуалистическом направлении «представлено либеральное крыло буржуазных ученых» ${ }^{30}$. В результате дуалисты фактически были отнесены к разряду заблуждающихся, в то время как монисты - к разряду классовых противников. Так, в 6-ти томном Курсе международного права по поводу этих теорий говорилось следующее: «Подвергая критическому разбору основные буржуазные теории, советская наука осуждает узость и юридический догматизм дуалистической теории, ограничивающейся анализом формального соотношения международного и внутригосударственного права, и антинаучный и реакционный характер обеих монистических теорий (т.е. теории «примата» внутригосударственного права и теории «примата» международного права), искажающих действительность в угоду империализма» ${ }^{31}$.

В противовес монистической и дуалистической концепций соотношения международного и внутригосударственного права была выдвинута и «советская» или «социалистическая» доктрина ${ }^{32}$.

Суть ее заключалась в том, что, признавая правильность положения дуалистической теории в части того, что международное и внутригосударственное право представляют собой две самостоятельные правовые системы, не подчиненные одна другой, советские юристы-международники вместе с тем подчеркивали их взаимосвязь и даже взаимозависимость. Было введено понятие «соприкосновения» правовых норм, принадлежащих к двум различным системам права, которое «происходит отнюдь не как подчинение одной системы права другой, а как взаимное согласование, взаимное дополнение, конкретизация одних норм 
с помощью других, или, наконец, как коллизия этих норм, требующая специальных способов для своего разрешения» ${ }^{33}$.

Считалось, что в отличие от социалистической доктрины дуалисты не вышли за рамки формально-догматического подхода ${ }^{34}$, «увлеклись анализом особенностей отношений международного и внутригосударственного права и настолько их гипертрофировали, что не признали возможным соотношение правовых систем и их элементов между собой» ${ }^{35}$. На самом деле это мало соответствовало действительности. Тот же Г. Трипель в своих работах исследовал многие вопросы взаимосвязи между обоими правопорядками: рецепцию и репродукцию положений международного права внутригосударственным правом и наоборот; отсылку одного права к другому; перенесение действия норм одной правовой системы в рамки другой и т. д. При этом он прямо писал о том, что «основной темой его дискуссии является исследование взаимоотношений между двумя этими системами права ${ }^{36}$. Он подчеркивал, что «для того, чтобы международное право смогло выполнить свою задачу, оно постоянно должно обращаться за помощью к внутреннему праву. Без него оно во многих отношениях является совсем бессильным» ${ }^{37}$. Что касается другого представителя дуалистической концепции - Д. Анцилотти, то, как не раз отмечалось в литературе ${ }^{38}$, он достаточно подробно остановился на такой форме связи международного и национального права, как отсылка. Таким образом, по основным выводам советская и дуалистическая концепции между собой фактически ничем принципиально не отличалась. И здесь и там присутствовал общий вывод о том, что международное и внутригосударственное право являются самостоятельными нормативными правовыми системами, которые взаимодействуют друг с другом, но имеют специфические субъекты и источники права, а главное - самостоятельные объекты правового регулирования. Международное право регулирует межгосударственные отношения, а национальное право - внутригосударственные отношения. Каждая является высшей в своей сфере. Но принять на вооружение «буржуазную» теорию было нельзя. Отсюда и возникла задача установления принципиальных отличий дуалистической и советской концепций соотношения разнотипных правовых систем. Думается, что, решая эту задачу, именно советская доктрина в целях обоснования своего самостоятельного подхода к вопросу о соотношении правовых систем несколько гипертрофировала идею дуалистов о независимости этих систем друг от друга ${ }^{39}$. 
Установившаяся определенность продолжалась недолго. Уже в конце 50-х, начале 60-х годов прошлого века в нашем государстве произошли события, потребовавшие пересмотра сложившихся было представлений о содержании «традиционных» концепций соотношения международного и национального права.

\section{Ratio of Legal Systems. Part 1. "Traditional" Doctrines on the Ratio of International and National Law}

(Summary)

Boris I. Nefedov*

Different approaches to the ratio of legal systems have been expressed by numerous authors during the entire period of the existence of international law, beginning with the period of its formation, but they were initially formalized in the form of "traditional" fundamental theoretical concepts and doctrines in the middle of the twentieth century, and only in the USSR. The very appearance of the relevant theoretical formations and the evolution of ideas about them later on, were caused by the existing level of development of social relations, as well as changes in the social and political system and the true interests of our government in the specific historical conditions.

Thus, the pre-revolutionary Russian authors of the late XIX - early XX century were mostly supporters of the dualistic approach, but after the establishment of the Soviet Union and until the mid-50's of the twentieth century, during the ratio of international and domestic law actually dominated the state-monistic approach, although technically it was not officially expressed at the time. Since the mid 50's of the previous century the Soviet doctrine again moved to the position of dualism. It was during this period, that in the domestic doctrine a formalization of "traditional" fundamental theoretical concepts of different views on the relation of international and domestic law were created. In this case, there were not three-, as is commonly believed, but four concepts - three bourgeois (two monistic and dualistic) and a Soviet.

Keywords: the ratio of international and domestic law; monistic concept; dualistic concept; the Soviet concept.

\footnotetext{
* Boris I. Nefedov - Doctor of Laws, assistant professor, Vice Provost for Research of the Omsk Academy of Law.
} 
${ }^{1}$ Обычно в качестве таковых в литературе упоминаются Н.А. Безбородов, О.О. Эйхельман и Э.К. Симсон. См. например: Левин Д. Б. Наука международного права в России в конце XIX и начале XX века.- М., 1982. С. 68.

${ }^{2}$ См.: Мартенс Ф.Ф. Современное международное право цивилизованных народов. СПб., 1895, Т. 1; Капустин М.Н. Обозрение предметов международного права. М., 1856. Вып. 1-4.; Даневский В.П. Пособие по изучению истории и системы международного права. Харьков. 1892. Вып. 1-2; Казанский П. Е. Введение в курс международного права. Одесса., 1901.; Иванов Н.П. Характеристика международных отношений и международного права в историческом развитии. Казань., 1874; Жихарев С.А. Россия в среде европейских народов по данным истории международных общения и права в 18 и 19 вв. Историко-юридические очерки. СПб., 1910 и др.

${ }^{3}$ Мартенс Ф.Ф. Современное международное право цивилизованных народов. СПб., 1895. Цит. по Кодан С.В. Исторический контекст взаимодействия национального и международного права в Российской империи (ХУ11 - начало XX века) // Международное и внутригосударственное право в условиях глобализации: проблемы теории и практики : материалы междунар. науч. конф. 25-28 апр. 2011 г. М. : РАП, 2012. С. 98. ${ }^{4}$ См.: Стучка П.И. Мой путь и мои ошибки // Советское государство и революция права, 1931, № 5-6. С. 70.

${ }^{5}$ См., например, 3 Вышинский А. Я. Вопросы международного права и международной политики. М,, 1949. С. 481.

${ }^{6}$ Перетерский И. С. Очерки международного частного права РСФСР. М. 1924 С. 18.

${ }^{7}$ Он просуществовал как принцип вплоть до 50-х годов, а в отдельных работах дожил почти до 1990-х годов 20-го века. См.: Международное право: учебник / отв. Ред. В.И. Кузнецов, Б.Р. Тузмухамедов. 2-е изд., перераб. и доп. М. : Норма, 2007. С. 34.

${ }^{8}$ Голунский С. А., Строгович М. С. Теория государства и права. М. 1940. С. 301. Такого же мнения придерживался Е.А. Коровин. См.: Коровин Е. А. Пролетарский интернационализм и международное право. М., 1959 и др.

9 Пашуканис Е. Очерки по международному праву.- М.,1935.- С.17-18.

${ }^{10}$ Коровин Е. А. Международное право переходного периода.- М.,1924.- С.13.

${ }^{11}$ Капустин А. Я. Конституция России о соотношении международного и российского права // Конституции России 10 лет: опыт реализации: опыт реализации : материалы всерос. науч.-практ. конф. Тюмень: Изд-во Тюмен. гос. ун-та. 2003. С. 124.

${ }^{12}$ Курс международного права: в 7 т. М.: Наука, 1989. Т. 1. С. 277.

13 Тункин Г. И. Основы современного международного права. 1956. С. 11-12. Его же. Вопросы теории международного права. 1962. С. 66-175.

14 Общим для этих концепций было то, что исходя из правильной в принципе посылки, что государство должно выполнять свои международные обязательства, они пришли к неверным выводам о том, что национальное право должно подчиняться международному праву, помимо государства и независимо от его воли.

${ }^{15}$ См., напр.: Kelsen H. Das Problem der Sbuveranitat und Theorie des Völkerrechts. Tübingen 1920 ; Kelsen H. Algemeine Sltatslehre. Berlin, 1925; Kelsen H. Reine Rechtslehre. Lpz, 1934; Kelsen H. General theory of law and state. Camb. (Mass.), 1945.

${ }^{16}$ См., напр.: Scelle G. Precis de droit des gens, principes et systematique-Paris: Recueil Sirey, 1932/34. t. 1 ; Scelle G. De la pretendue inconstitutionnalite interne des tvaites. Revue de droit public et de sciences poliliques, 1952; Scelle G. Precis du droit des gens P., 1934. 
${ }^{17}$ Отметим, что в дальнейшем, в своей работе «Общая теория норм» (опубликованной посмертно Институтом Ганса Кельзена) Г. Кельзен пересмотрел свои взгляды на основную норму и отнес ее к числу юридических фикций: «Основная норма является не гипотезой, как я сам характеризовал ее иногда... а фикцией». См.: Kelsen H. Allgemeine Theorie der Normen. Wien. 1979.

${ }^{18}$ Kelsen H. The Pure Theory of Law and Analitical Jurisprudence, Harward Law Review, November 1941. Цит. по кн. А. Я. Вышинского, «Вопросы международного права и международной политики», Госюриздат, 1949, стр. 472-473.

${ }^{19}$ Scelle G. Cours de droit international public. Paris. 1948. P.104.

${ }^{20}$ CM.: Wenzel M. Juristische Grundproblerne. 1920

${ }^{21}$ CM.: Kaufmann E. Die Rechtskraft des internationaleri Rechts und das Verhaltniss der Staatsgesetsgebun-gen und der Staatsorgane /u demselben, Stuttgart. 1899.

${ }^{22}$ Zorn A. Crundzüge des Volkerrechts. Leipzig: J.J. Weber.1903. P.315.

${ }^{23}$ Курс международного права : в 6 т. М. : Наука, 1967. Т. 1. С. 209.

${ }^{24}$ Блищенко И. П. Международное и внутригосударственное право. М., 1960. С.238.

${ }^{25}$ Курс международного права : в 6 томах. М.: Наука, 1967. Т. 1. С. 199.

${ }^{36}$ Triepel H. Völkerrecht und Landesrecht. Leipzig, 1899. S.19.

${ }^{27}$ Анцилотти Д. Курс международного права. М. : Иностр. лит. 1961. Т. 1. С. 66.

${ }^{38}$ Там же С. 69.

${ }^{29}$ Оппенгейм Л. Международное право. М., 1948. Т. 1. С. 55.

${ }^{30}$ Курс международного права : в 7 т. М. : Наука, 1989. Т. 1. С. 278.

${ }^{31}$ Курс международного права : в 6 т. М. : Наука, 1967. Т. 1. С. 206. Правда, Д.Б. Левин по поводу таких коллизий считал, что «в практике Советского Союза и стран народной демократии коллизии между нормами международного права и нормами внутригосударственного права невозможны». См.: Левин Д.Б. Основные проблемы современного международного права. М. : Госюриздат, 1958. С. 128.

${ }^{32}$ См., напр.: Ладыженский А.М. К вопросу о взаимоотношении внутригосударственных и международно-правовых норм // Ученые записки Ростов. на /Д гос. ун-та. 1957. Т. 68. Вып. 4, Ч. 1, С. 60-61; Левин Д.Б. Основные проблемы современного международного права. М.: Юриздат, 1958. С. 114-115; Тункин Г. И. Основы современного международного права. М., 1956. С. 8-9; Шуршалов В.М. Основные вопросы теории международного договора. М: Изд-во АН СССР, 1959. С. 314 и др.

${ }^{33}$ Курс международного права: в 6 т. М. : Наука, 1967. Т. 1. С. 204-207.

${ }^{34}$ Там же. С. 210

${ }^{35}$ См.: Буткевич В. Г. Соотношение внутригосударственного и международного права. M., 1982. C. 53.

${ }^{36}$ Triepel H. Les rapports entre le droit intern et le droit international. - Recueil des cours de L'Academie de droit international, 1925, P. 92.

${ }^{37}$ Ibid., P.106.

${ }^{38}$ См., например: Мюллерсон Р.А. Соотношение международного и национального права. М., 1982. С. 10.

${ }^{39}$ Не случайно уже к середине 90-х годов XX века в литературе о советской доктрине практически уже не встретишь упоминания, речь идет только о приверженности или отрицании дуалистического подхода. 